\title{
CLINICAL SCIENCE
}

\section{NON-ASTHMATIC PATIENTS SHOW INCREASED EXHALED NITRIC OXIDE CONCENTRATIONS}

\author{
Beatriz M. Saraiva-Romanholo, ${ }^{\mathrm{I}}$ Fabio S. Machado, ${ }^{\mathrm{I}}$ Francine M. Almeida, ${ }^{\mathrm{I}}$ \\ Maria do Patrocínio T. Nunes, ${ }^{,}$Milton A. Martins, ${ }^{1}$ Joaquim E. Vieira ${ }^{I I}$
}

doi: 10.1590/S1807-59322009000100002

\begin{abstract}
Saraiva-Romanholo BM, Machado FS, Almeida FM, Nunes MPT, Martins MA, Vieira JE. Non-asthmatic patients show increased exhaled nitric oxide concentrations. Clinics. 2009;64(1):5-10.
\end{abstract}

OBJECTIVE: Evaluate whether exhaled nitric oxide may serve as a marker of intraoperative bronchospasm.

INTRODUCTION: Intraoperative bronchospasm remains a challenging event during anesthesia. Previous studies in asthmatic patients suggest that exhaled nitric oxide may represent a noninvasive measure of airway inflammation.

METHODS: A total of 146,358 anesthesia information forms, which were received during the period from 1999 to 2004, were reviewed. Bronchospasm was registered on 863 forms. From those, three groups were identified: 9 non-asthmatic patients (Bronchospasm group), 12 asthmatics (Asthma group) and 10 subjects with no previous airway disease or symptoms (Control group). All subjects were submitted to exhaled nitric oxide measurements (parts/billion), spirometry and the induced sputum test. The data was compared by ANOVA followed by the Tukey test and Kruskal-Wallis followed by Dunn's test.

RESULTS: The normal lung function test results for the Bronchospasm group were different from those of the asthma group (p $<0.05)$. The median percentage of eosinophils in induced sputum was higher for the Asthma [2.46 (0.45-6.83)] compared with either the Bronchospasm [0.55 (0-1.26)] or the Control group [0.0 (0)] $(\mathrm{p}<0.05)$; exhaled nitric oxide followed a similar pattern for the Asthma [81.55 (57.6-86.85)], Bronchospasm [46.2 (42.0 -62.6] and Control group [18.7 (16.0-24.7)] $(\mathrm{p}<0.05)$.

CONCLUSIONS: Non-asthmatic patients with intraoperative bronchospasm detected during anesthesia and endotracheal intubation showed increased expired nitric oxide.

KEYWORDS: Nitric Oxide; Bronchial Spasm; Anesthesia; Sputum and Asthma.

\section{INTRODUCTION}

The incidence of perioperative bronchospasm is very low, close to $0.17 \%$, but may reach $2.19 \%$ among patients with obstructive disease. ${ }^{1}$ Up to $45 \%$ of asthmatic patients present wheezing during anesthetic induction, while $16 \%$ of non-asthmatic patients show the same event. ${ }^{2}$

Anesthetists should be aware of the precipitating factors, recognize the signs and be prepared to undertake a logical plan for management of perioperative bronchospasm. In patients with bronchial hyperreactivity, airway instrumentation

${ }^{\mathrm{I}}$ Department of Medicine, Faculdade de Medicina, Universidade de São Paulo - São Paulo/SP, Brazil.

"Division of Anesthesiology, Hospital das Clínicas, Faculdade de Medicina, Universidade de São Paulo - São Paulo/SP, Brazil.

Email: joaquimev@usp.br

Tel. : 55.11.3082.4076

Received for publication on July 29, 2008

Accepted for publication on August 25, 2008 may evoke life-threatening bronchospasm, perioperative complications, and prolonged intensive care treatment., ${ }^{2,3}$

Despite major advances in our understanding of the clinical management of intraoperative bronchospasm, it remains a challenging situation for anesthesiologists in clinical practice. Airways of patients with bronchial hyperreactivity are characterized by exaggerated bronchoconstriction in response to a variety of stimuli. ${ }^{4}$

Nitric oxide (NO) of endogenous origin is present in exhaled breath. ${ }^{5} \mathrm{NO}$ participates in the physiologic regulation of bronchomotor tonus, but is also involved in diseases, such as asthma. ${ }^{6}$ An increase in the concentration of exhaled NO (ENO) has been described with bronchial asthma. ${ }^{7,8}$ Previous studies have raised the possibility that the measurement of NO concentrations in expired air may represent a noninvasive measure of lower airway inflammation. ${ }^{9,10}$ The aim of this investigation was to address the possibility of using exhaled $\mathrm{NO}$ as a marker of intraoperative bronchospasm. 


\section{METHODS AND MATERIALS}

The present investigation was approved by the Research Ethics Committee of the University of São Paulo Medical School and informed written consent was obtained from patients (ClinicalTrials.gov protocol NCT00666510). In order to find eligible patients, the first step was to identify patients with registered intraoperative bronchospasm during tracheal intubation. The identified patients had written statements of intraoperative bronchospasm in their registered anesthesia forms and received subsequent measures to overcome that adverse event. These measures generally included administration of a bronchodilator via a nebulizer inside the tracheal tube or intravenously. By review of 146,358 anesthetic-surgical case forms recorded by the Anesthesiology Division from 1999 to 2004 (Figure 1), those with registered bronchospasm were identified. From these records, we did not include those who met the exclusion criteria (severe systemic disease, liver transplantation, Chronic Obstrutive Pulmonary Disease - COPD, autoimmune disease, corticoid therapy, cancer, elderly (above 60 years) or young (below 16 years), pregnancy, smoking history at the time of surgery and identified asthma), which may affect the ENO measurement. Eligible patients were invited by phone to return to the hospital for a clinical assessment. After the interview and clinical exam, the patients, all of whom underwent bronchospasm during

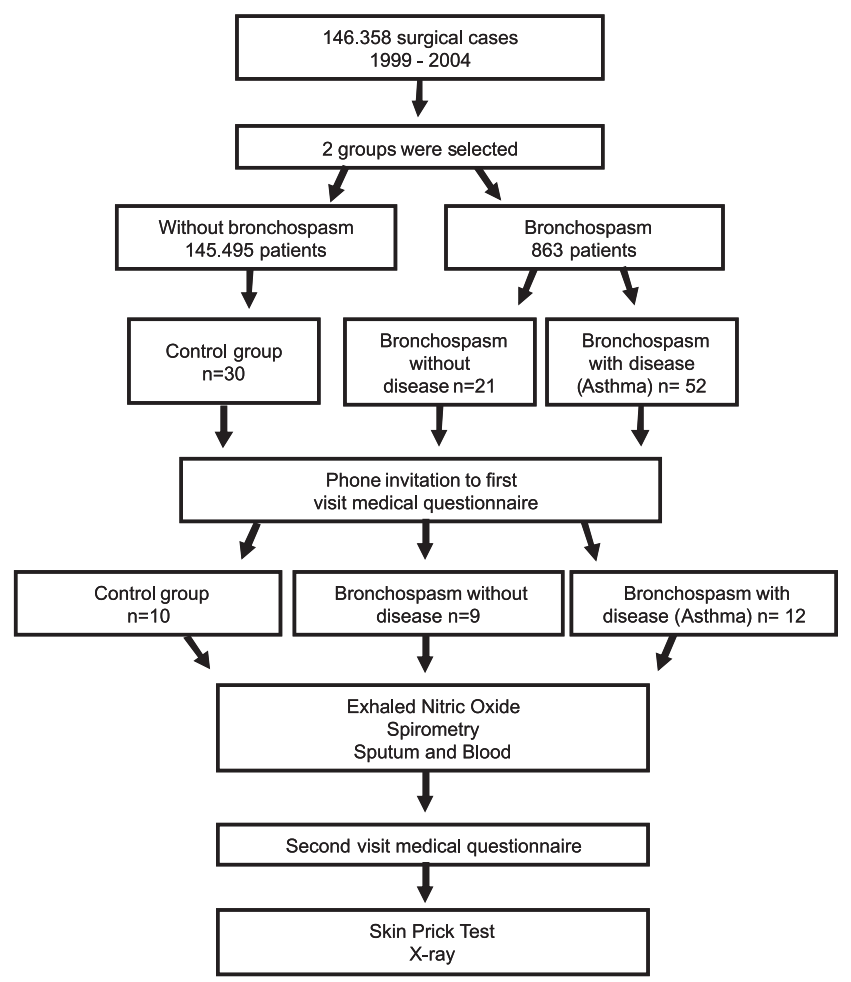

Figure 1 - Study design intubation, were further classified into two groups, nonasthmatics (9 subjects) and asthmatics (12 patients). Importantly, none of the asthmatic patients had a clinical diagnosis of asthma before this clinical assessment or as of the chosen anesthetic procedure. In addition, a third group of 10 subjects, who had undergone a surgical procedure under general anesthesia without any sign of respiratory adverse events or any history of intraoperative bronchospasm, was selected as a control group. These subjects were enlisted from the case forms that were described previously.

Patients were seen for clinical examination on two visits within one month. During the first visit, exhaled air was collected for the measurement of ENO with spirometry, which was the primary endpoint of the study. In addition, induced sputum was collected and blood was collected, which was then submitted to an IgE measurement. Additional laboratory tests were performed to exclude other systemic diseases. During the second visit, each of the subjects was submitted to a routine follow-up examination, skin allergy prick tests and chest radiographs (Figure 1). In addition, spirometry was performed on all subjects according to the guidelines put forth by the American Thoracic Society (ATS) and using the ATS standardization for the Koko Spirometer (POS Instrumentation, Inc., Louisville, CO, USA). ${ }^{11,12}$

Participants also completed a medical questionnaire about asthma medications, concomitant illnesses (including allergies), history of cigarette smoking and events that triggered the current asthma. None of the subjects were found to have or have had any of the following: heart disease, diabetes, hypertension, renal insufficiency, elevated serum creatinine concentrations, stroke, altered EKG, COPD, cancer, emergency surgery or current pregnancy.

The asthmatic patients were studied during a clinically stable period. The subject characteristics are summarized in Table 1. ENO was collected offline and the evaluation was made before spirometry. They were required to inhale orally through a mouthpiece containing a $0.3 \mu \mathrm{m}$ bacterial HEPA filter (TROX Technik Ltda, SP, Brazil) ${ }^{8}$ attached to the sampling kit (Sievers Instruments Inc., Boulder, CO, USA).

Following international recommendations, this kit contains a pressure gauge and an inspiratory filter that washes out the NO concentration from the inhaled air. In order to avoid a sample from dead space gas, the subject was instructed to breathe through the sampling kit for a minimum of two breaths to ensure tidal volumes and to use a nose clip to avoid nasal contamination. ${ }^{13,14}$ During the next expiration, the volunteer had to produce a breath pressure of $12 \mathrm{~cm}$ $\mathrm{H}_{2} 0$, which was indicated by a pressure gauge reported flow rate of $200 \mathrm{~mL} . \mathrm{s}^{-1}$ when pushed into a stainless steel valve on the sampling kit after 3 seconds of exhalation, avoiding 
Table 1 - Subject characteristics

\begin{tabular}{|c|c|c|c|}
\hline Group & $\begin{array}{l}\text { Control } \\
(n=10)\end{array}$ & $\begin{array}{c}\text { Bronchospasm } \\
(\mathrm{n}=9)\end{array}$ & $\begin{array}{c}\text { Asthma } \\
(n=12)\end{array}$ \\
\hline $\begin{array}{l}\text { Age Range, } \\
\text { yr,Mean } \pm \text { SD }\end{array}$ & $\begin{array}{c}(39-51) \\
41.90 \pm 3.54\end{array}$ & $\begin{array}{c}(17-60) \\
37.22 \pm 15.37\end{array}$ & $\begin{array}{c}(19-53) \\
30.33 \pm 11.04\end{array}$ \\
\hline \multicolumn{4}{|l|}{ Sex } \\
\hline Female & 8 & 6 & 8 \\
\hline Male & 2 & 3 & 4 \\
\hline Current smoker & 0 & 1 & 1 \\
\hline Past smoker & 2 & 0 & 2 \\
\hline History of rhinitis & 0 & 0 & 10 \\
\hline $\begin{array}{l}\text { History of } \\
\text { dermatitis }\end{array}$ & 0 & 1 & 1 \\
\hline $\begin{array}{l}\text { History of } \\
\text { sinusitis }\end{array}$ & 0 & 0 & 7 \\
\hline $\begin{array}{l}\beta_{2} \text {-agonist or } \\
\text { corticosteroids }\end{array}$ & 0 & 0 & 12 \\
\hline $\begin{array}{l}\text { Gastroesophageal } \\
\text { reflux disease }\end{array}$ & 0 & 0 & 2 \\
\hline
\end{tabular}

Data from medical questionnaire. Age is presented as mean \pm SD.

the dead space gas, and continued for about 2 seconds for a collected volume larger than $50 \mathrm{~mL}$ (each sample). ${ }^{14}$ The breath sample was collected in an NO impermeable reservoir bag (Mylar bag; Sievers Instruments Inc. Boulder, CO, USA) with a volume capacity of $1.5 \mathrm{~L}$. The subject repeated the procedure until three bags were filled. These bags were sealed and immediately analyzed for the concentration of ENO by chemiluminescence (Sievers model NOA 280, Boulder, CO, USA). ${ }^{8} 13$ The variability among measured NO concentrations was less than $10 \%$ and the recorded result was the average of the ENO values for the three bags.

Pulmonary function tests were performed for all subjects using an ATS standardized Koko Spirometer (POS Instrumentation, Inc., Louisville, CO). ${ }^{11,12}$ Spirometry was performed before and after beta- 2 agonist inhalation. After the spirometric measurement, the sputum was induced with $3 \%$ hypertonic saline concentrations in an aerosol formulation from an ultrasonic nebulizer. ${ }^{15}$

Sputum samples were visually separated from saliva with the help of an inverted microscope and divided into two aliquots. One part was spread over a glass slide prior to fixation and staining with Diff Quick (Sigma-Aldrich, SP, Brazil). ${ }^{16}$ The second aliquot was treated with $0.1 \%$ dithiothreitol (Sigma-Aldrich, SP, Brazil) and submitted to a total cell count with a hemocytometer (Neubauer chamber). ${ }^{17}$

In vitro tests for the quantitative determination of $\mathrm{IgE}$ in human serum and skin tests to detect fungi, pollen, mites, cat, dog, and cockroach allergies were performed according to routine laboratory and standard procedures. ${ }^{18,19}$

\section{Statistical analysis}

Data are presented as means and standard deviations (SD) or medians and $25^{\text {th }}$ and $75^{\text {th }}$ percentiles. To evaluate ENO values, cytological data and IgE titers, Kruskal-Wallis non-parametric analysis of variance followed by Dunn's test were used. To compare spirometry data, analysis of variance followed by the Tukey test was used. A p value lower than 0.05 was considered significant.

\section{RESULTS}

A total of 863 documented intraoperative bronchospasms with relevant histories were identified among the 146,358 forms that were obtained during the study period. Of these, 277 were excluded due to liver transplantation, COPD, autoimmune disease, corticoid therapy, and cancer. In addition, we excluded 175 older patients (> 60 years old), 139 children (age $\leq 16 \mathrm{yr}$ ) and 39 smokers. Finally, 160 patients with bronchospasms that could not be reached by phone or regular mail were excluded. Thus, of the remaining 73 patients, 52 patients with a documented history of asthma and 21 patients who were supposedly non-asthmatic but had a history of bronchospasm were selected as the study group.

After selection of study patients based on their anesthesia records, those with an established diagnosis of asthma were asked to come in for clinical examination. Of the 52 who had an established asthmatic condition, 13 were reached by phone; of the 13, 12 accepted and 1 declared that she was pregnant and was thus ineligible. Of the 21 non-asthmatic patients with a history of bronchospasm under intraoperative anesthesia, we were able to contact 18 subjects. Of the 18,6 refused to participate, 1 could not perform the pulmonary function test correctly, resulting in test errors, and 2 were diagnosed with mild COPD from the first medical examination; in total, these 9 patients were excluded from the study. The remaining 9 patients had shown no signs and no history of any respiratory disease after the first medical examination and were considered as being free of pulmonary disease.

A control group was selected from healthy volunteers with no adverse events reported in the anesthesia records (Table 2, Figure 1).

The anesthetics used for the study patients were: propofol (1.5 to $2.5 \mathrm{mg} \cdot \mathrm{kg}^{-1}$ ) alone or in association with midazolam $\left(0.1 \mathrm{mg} \cdot \mathrm{kg}^{-1}\right)$, fentanyl (5 to $\left.10 \mathrm{mcg} \cdot \mathrm{kg}^{-1}\right)$ or alfentanyl (10 to $\left.20 \mathrm{mcg} \cdot \mathrm{kg}^{-1}\right)$ and rocuronium $\left(0.6 \mathrm{mg} \cdot \mathrm{kg}^{-1}\right)$ during the induction of anesthesia. There was no record of difficult intubation or insufficient anesthetic infusion resulting in inadequate anesthesia depth among subjects in the observed group. For maintenance, all patients received isoflurane or sevoflurane. 
Saraiva-Romanholo BM et al.

Table 2 - Inflammatory markers (median [25\%-75\%])

\begin{tabular}{lccc}
\hline Group & $\begin{array}{c}\text { Control Median } \\
{[25 \%-75 \%]}\end{array}$ & $\begin{array}{c}\text { Bronchospasm Median } \\
{[25 \%-75 \%]}\end{array}$ & $\begin{array}{c}\text { Asthma Median } \\
{[25 \%-75 \%]}\end{array}$ \\
\hline CTC/mL.10 IS & $0.36[0.26-0.90]$ & $1.30[0.23-2.60]$ & $1.08[0.61-2.00]$ \\
EOS (\%) IS & $0[0-0]$ & $0.55[0-1.26]$ & $2.46[0.45-6.83 *]$ \\
Neu (\%) IS & $40.45[24.40-57.00]$ & $55.20[21.89-63.92]$ & $63.78[25.06-78.10]$ \\
IgE UL/mL Serum & $35.50[14.00-61.00]$ & $110.00[67.47-395.50]$ & $523.00[193.00-1220.00 *]$ \\
ENO (ppb) & $18.70[16.00-24.70]$ & $46.20[42.00-62.60 * *]$ & $81.55[57.60-86.85 *]$ \\
& & & NS \\
\hline
\end{tabular}

CTC/mL. $10^{6}$ IS, total cell count in the induced sputum; EOS (\%) IS, percentage of eosinophils; Neu (\%) IS, percentage of neutrophils; IgE UI.ml ${ }^{-1}$ Serum, immunoglobulin E in the serum; ENO (ppb), exhaled nitric oxide. *Asthma compared with Control; **Bronchospam compared with Control; NS, Non Significant.

ENO was higher in the asthmatic patients than in the control patients $(\mathrm{p}=0.001)$, but the levels in asthmatic patients were similar to those in the group with bronchospasm (Table 2, Figure 2). The bronchospasm group's ENO was significantly different from the ENO for the control group $(\mathrm{p}=0.005)$. Pulmonary function test results showed that the asthma group was significantly different from the control group. The bronchospasm group had a normal spirometry test and no differences were observed compared with the control group for this test (Table 3 ).

The percentage of eosinophils in the sputum was significantly different between the asthmatics and controls (Table 2). The eosinophil percentage from the bronchospasm group did not differ significantly from that of the asthmatics; the median was very near zero, close to that for the control group. All patients showed slightly elevated neutrophil levels, but asthmatics had higher concentrations that the other groups. The total cell counts did not show any differences by group (Table 2).



Figure 2 - Exhaled nitric oxide parts per billion (ENO ppb) measurements from healthy subjects (control) and subjects with history of bronchospasm in intraoperative period (Bronchospasm and Asthma). The boxplot shows the $25^{\text {th }}, 50^{\text {th }}$ and $75^{\text {th }}$ percentiles, with the extreme bars representing the $10^{\text {th }}$ and $90^{\text {th }}$ percentiles. ENO (ppb) measure, $* \mathrm{p}=0.001$ compared with control and $* * \mathrm{p}=0.005$ compared with control

Table 3 - Spirometric data

\begin{tabular}{|c|c|c|c|c|}
\hline Group & Control Mean \pm SD & Bronchospasm Mean \pm SD & Asthma Mean \pm SD & $\mathrm{P}$ \\
\hline FVCpred(\%) & $107.90 \pm 13.94$ & $98.78 \pm 6.85$ & $94.58 \pm 20.83$ & NS \\
\hline FVCafter $(\%)$ & $105.90 \pm 12.90$ & $98.67 \pm 7.94$ & $97.92 \pm 19.41$ & NS \\
\hline $\mathrm{FEV}_{1} \operatorname{pred}(\%)$ & $108.80 \pm 11.99$ & $99.44 \pm 9.79$ & $83.83 \pm 18.48 * \dagger$ & $\begin{array}{c}* 0.0003 \\
\dagger 0.020\end{array}$ \\
\hline $\mathrm{FEV}_{1}$ after $(\%)$ & $109.30 \pm 12.39$ & $103.22 \pm 8.42$ & $91.00 \pm 19.59$ & NS \\
\hline $\mathrm{FEV}_{1} / \mathrm{FVCpred}(\%)$ & $101.40 \pm 6.10$ & $101.89 \pm 6.15$ & $89.00 \pm 11.65^{* \dagger}$ & $\dagger * 0.002$ \\
\hline $\mathrm{FEV}_{1} / \mathrm{FVCafter}(\%)$ & $103.20 \pm 4.52$ & $105.44 \pm 4.33$ & $93.83 \pm 12.50 \dagger$ & $† 0.005$ \\
\hline $\mathrm{FEF}_{25-75}$ pred (\%) & $104.00 \pm 24.79$ & $95.78 \pm 27.64$ & $61.83 \pm 24.79 * \dagger$ & $\begin{array}{c}* 0.001 \\
\dagger 0.01\end{array}$ \\
\hline $\mathrm{FEF}_{25-75}$ after $(\%)$ & $112.50 \pm 21.78$ & $107.89 \pm 28.07$ & $74.50 \pm 30.49 * \dagger$ & $\begin{array}{c}* 0.003 \\
\dagger 0.001\end{array}$ \\
\hline
\end{tabular}

FVC - Forced vital capacity; FEV - Forced expiratory volume in 1s; FEV,/FVC; relation between FEV and FVC; FEF ${ }_{25 \%}$ F5\% $_{1}$ - Forced expiratory flow between $25 \%-75 \%$ of vital capacity: Pred - expected for age and height and After- after $\beta_{2}$-agonist. * Compared with Control Group; $\uparrow$ Compared with Bronchospasm; NS Non Significant. 
The serum IgE levels were greater for the asthma group (523.00 [193.00-1220.00]) compared with those for the control group (35.50 [14.00-61.00]), but they were not different from the levels in the bronchospasm group (110.00 [67.47-395.50]); again, the asthmatics differed from the control group but not from the bronchospasm group (Table 2 ). The prick test showed a variety of positive results with slightly higher positivity among asthmatics.

\section{DISCUSSION}

Asthma is a serious and widespread epidemiological problem, with a relatively high level of prevalence in the city of São Paulo. ${ }^{20}$ This study showed high ENO levels in patients with registered bronchospasm induced by tracheal intubation during anesthesia but no history of asthma disease. This result supports the notion that NO is associated with airway hyperresponsiveness, although it raises the question of whether it also reflects airway inflammation.

Several studies have shown that NO is an inflammatory marker as well as a surrogate measure of airway inflammation in patients with asthma. ${ }^{21-23}$ In this study, we observed elevated NO concentrations in the bronchospasm group, which was comprised of patients with no previous history of airway inflammation. It has been shown that measurements of ENO may represent a noninvasive approach for assessing the degree of current airway inflammation. ${ }^{24-26}$ However, some studies did not find a correlation between ENO and bronchial hyperresponsiveness. ${ }^{16,27} \mathrm{NO}$ is considered an important mediator of countless physiological processes in the respiratory system as well as a factor that is involved in the pathophysiology of asthma. ${ }^{25}$ Thus, it seems reasonable to consider $\mathrm{NO}$ as a potential marker of airway hyperresponsiveness as well as airway inflammation.

Despite the bronchospasm group showing a wide age range, studies do not show a consistent relationship between $\mathrm{NO}$ and age for adults. ${ }^{28}$ In this subsample of patients, serum IgE and induced sputum cells were slightly elevated, although in the normal range. Also, the spirometry data did not show lower values for this subgroup. It is interesting to note that these normal results precluded the diagnosis of asthma, but the elevated NO levels observed in the bronchospasm group indicates that they had hyperresponsive airways.

Induced sputum is a reliable test that enables differentiation of healthy airways from asthmatic airways, for which eosinophils are considered an important marker. ${ }^{17}$ Some studies have shown that induced sputum is a useful and safe evaluation method for the detection of asthma and airway inflammation. ${ }^{29-31}$ Our patients that were found to have high NO concentrations did not show eosinophil results that were compatible with an inflammatory airway, since inflammatory cells were not present in their induced sputum.

In a previous report, baseline airway hyperresponsiveness was related to $\mathrm{FEV}_{1}$ (Forced Expiratory Volume in the first second) but not to inflammatory parameters, such as ENO. ${ }^{32}$ By contrast, in our study, healthy patients with bronchospasm presented normal spirometry but had bronchospasms and higher ENO levels. Whether ENO could be considered a useful method to predict bronchial hyperresponsiveness for nonasthmatic patients remains to be shown. ${ }^{33,34}$ Although the anesthesiologist may deal with such an unexpected event pharmacologically, these patients may represent an at-risk population.

It is important to note that a standardized bronchial provocation $\mathrm{PC}_{20}$ would have greatly enriched our study. However, we thought that this test would expose patients to unnecessary risk, particularly the patients with bronchospasm who showed elevated NO values, which is suggestive of airway hyperreactivity. The absence of this test certainly impaired the sensitivity of our protocol, but we decided against using this test for patient safety. Nevertheless, it would be reasonable to consider ENO as an associated marker for hyperresponsiveness that is similar to bronchoprovocation, but with lower risks. ${ }^{35-37}$ In addition, some authors have suggested that hyperresponsiveness may not be related to airway tissue inflammation..$^{38,39}$

In conclusion, the ENO concentrations were higher among non-asthmatic patients with intraoperative bronchospasm associated with endotracheal intubation. Although this report suggests a clinical role for monitoring ENO concentrations, the results should be interpreted with caution due to the cross-sectional nature of this study. A prospective longitudinal study is required in order to establish predictive correlations.

This work was supported by the following Brazilian scientific agencies: FAPESP, CNPq, PRONEX-MCT and FFM. 


\section{REFERENCES}

1. Olsson GL. Bronchospasm during anesthesia. A computer-aided incidence study of 136,929 patients. Acta Anaesthesiol Scand. 1987;31:244-52.

2. Pizov R, Brown RH, Weiss YS, Baranov D, Hennes H, Baker S, et al. Wheezing during induction of general anesthesia in patients with and without asthma. A randomized, blinded trial. Anesthesiology. 1995;82:1111-16.

3. Warner DO, Warner MA, Barnes RD, Offord KP, Schroeder DR, Gray DT, et al. Perioperative respiratory complications in patients with asthma. Anesthesiology. 1996;85:460-7.

4. National Institutes of Health. National Heart, Lung and Blood Institute. Global Strategy for Asthma Management and Prevention. Issued January, 1995. Updated 2005. [http://www.ginasthma.org]

5. Silkoff PE, McClean PA, Caramori M, Slutsky AS, Zamel N. A significant proportion of exhaled nitric oxide arises in large airways in normal subjects. Respir Physiol. 1998;113:33-8.

6. Gaston B, Drazen JM, Loscalzo J, Stamler JS. The biology of nitrogen oxides in the airways. Am J Respir Crit Care Med. 1994;149:538-51.

7. Prado CM, Leick-Maldonado EA, Kasahara DI, Capelozzi VL, Martins MA, Tiberio IFLC. Effects of acute and chronic nitric oxide inhibition in an experimental model of chronic pulmonary allergic inflammation in guinea pigs. Am J Physiol Lung Cell Mol Physiol. 2005;289:L67783.

8. Leme AS, Kasahara DI, Nunes MP, Martins MA, Vieira JE. Exhaled nitric oxide collected with two different mouthpieces: a study in asthmatic patients. Braz J Med Biol Res. 2002;35:1133-7.

9. Massaro AF, Mehta S, Lilly CM, Kobzik L, Reilly JJ, Drazen JM. Elevated nitric oxide concentrations in isolated lower airway gas of asthmatic subjects. Am J Respir Crit Care Med. 1996;153:1510-14.

10. Smith AD, Cowan JO, Brassett KP, Herbison GP, Taylor DR. Use of exhaled nitric oxide measurements to guide treatment in chronic asthma. N Engl Med. 2005; 352:2163-73.

11. National Institutes of Health. National Heart, Lung and Blood Institute. Global Strategy for Asthma Management and Prevention. Issued January, 1995. Updated 2002. NIH Publication. No 02-3659;2002.

12. American Thoracic Society. Standardization of spirometry. Am J Respir Crit Care Med 1995;152:1107-36.

13. American Thoracic Society. Recommendations for standardized procedures for the online and offline measurement of exhaled lower respiratory nitric oxide and nasal nitric oxide in adults and children. Am J Respir Crit Care Med. 1999;160:2104-17.

14. Kharitonov S, Alving K, Barnes PJ. Exhaled and nasal nitric oxide measurements: recommendations. Eur Respir J. 1997;10:1683-93.

15. Pizzichini E, Pizzichini MMM, Efthimiadis A, Hargreave FE, Dolovich J. Measurement of inflammatory indices sputum: effects of selection of sputum to minimize salivary contamination. Eur Respir J. 1996;9:117480 .

16. Van Rensen EL, Straathof KC, Veseselic-Charvat MA, Zwinderman AH, Bel EH, Sterk PJ. Effect of inhaled steroids on airway hyperresponsiveness, sputum eosinophils and exhaled nitric oxide levels in patients with asthma. Thorax. 1999;54:403-8.

17. Saraiva-Romanholo BM, Barnabe V, Carvalho AL, Martins MA, Saldiva $\mathrm{PH}$, Nunes Mdo P. Comparison of three methods for differential cell count in induced sputum. Chest.2003,124:1060-6.

18. Winter WE, Hardt NS, Fuhrman S. Immunoglobulin E: importance in parasitic infections and hypersensitivity responses. Arch Pathol Lab Med. 2000;124:1382-5.

19. Dreborg, S. Skin testing. The safety of skin tests and the information obtained from using different methods and concentrations of allergen. Allergy. 1993;48:473-5

20. Lima RG, Pastorino AC, Casagrande RR, Sole D, Leone C, Jacob CM. Prevalence of asthma, rhinitis and eczema in $6-7$ years old students from the western districts of São Paulo City, using the standardized questionnaire of the "International Study of Asthma and Allergies in Childhood" (ISAAC)-phase IIIB. Clinics. 2007;62:225-34.
21. Van Den Toorn LM, Prins JB, Overbeek SE, Hoogsteden HC, De Jongste JC. Adolescents in clinical remission of atopic asthma have elevated exhaled nitric oxide levels and bronchial hyperresponsivenes. Am J Respir Crit Care Med. 2000;162:953-7.

22. Kharitonov SA, O'Connor BJ, Evans DJ, Barnes PJ. Allergen-induced late asthmatic reactions are associated with elevation of exhaled nitric oxide. Am J Respir Crit Care Med. 1995,151:1894-99.

23. Zitt M. Clinical applications of exhaled nitric oxide for the diagnosis and management of asthma: a consensus report. Clin Ther. 2005;27:1238 50 .

24. Lanz MJ, Leung DYM, McCormick DR, Harbeck R, Szefler SJ, White CW. Comparison of exhaled nitric oxide, serum eosinophilic cationic protein, and soluble interleukin-2 receptor in exacerbations of pediatric asthma. Pediatr Pulmonol. 1997;24:305-11.

25. Barnes PJ, Kharitonov SA. Exhaled nitric oxide: a new lung function test. Thorax. 1996;51:233-7.

26. Baraldi E, Azzolin NM, Zanconato S, Dario C, Zacchello F. Corticosteroids decrease exhaled nitric oxide in children with acute asthma. J Pediatr. 1997;131:381-5.

27. Lim S, Jataknaon A, John M, Gilbey T, O'Connor BJ, Chung K, et al. Effect of inhaled budesonide on lung function and airway inflammation: assessment by various inflammatory markers in mild asthma. Am J Respir Crit Care Med 1999;159:22-30.

28. Jilma B, Kastner J, Mensik C, Vondrovec B, Hildebrandt J, Krejcy K, et al. Sex differences in concentrations of exhaled nitric oxide and plasma nitrate. Life Sci 1996;58:469-76.

29. Gibson PG, Henry RL, Thomas P. Noninvasive assessment of airway inflammation in children: induced sputum, exhaled nitric oxide, and breath condensate. Eur Respir J 2000;16:1008-15.

30. Jatakanon A, Lim S, Kharitonov SA, Chung KF, Barnes PJ. Correlation between exhaled nitric oxide, sputum eosinophils, and methacholine responsiveness in patients with mild asthma. Thorax. 1998;53:91-5.

31. Berlyne GS, Parameswaran K, Kamada D, Efthimiadis A, Hargreave FE. A comparison of exhaled nitric oxide and induced sputum as markers of airway inflammation. J Allergy Clin Immunol. 2000;106:638-44.

32. Ichinose M, Takahashi T, Sugiura H, Endoh E, Miura M, Mashito Y, et al. Baseline airway hyperresponsiveness and its reversible component: role of airway inflammation and airway calibre. Eur Respir J. 2000;15:24853.

33. Nogami H, Shoji S, Nishima S. Exhaled nitric oxide as a simple assessment of airway hyperresponsiveness in bronchial asthma and chronic cough patients. J Asthma 2003;40:653-9.

34. Del Giudice MM, Brunese FP, Piacentini GL, Pedulla M, Capristo C, Decimo F, et al. Fractional exhaled nitric oxide (FENO), lung function and airway hyperresponsiveness in naïve atopic asthmatic children. $\mathrm{J}$ Asthma. 2004;41:759-65.

35. Langley SJ, Goldthorpe S, Custovic A, Woodcock A. Relationship among pulmonary function, bronchial reactivity, and exhaled nitric oxide in a large group of asthmatic patients. Ann Allergy Asthma Immunol. 2003;91:398-404.

36. Spallarossa D, Battistini E, Silvestri M, Sabatini F, Fregonese L, Brazzola $\mathrm{G}$, et al. Steroid-naïve adolescents with mild intermittent allergic asthma have airway hyperresponsiveness and exhaled nitric oxide levels. J Asthma. 2003;40:301-10.

37. Dupont LJ, Rochette F, Demedts MG, Verleden GM. Exhaled nitric oxide correlates with airway hyperresponsiveness in steroid-naïve patients with mild asthma. Am J Resp Crit Care Med. 1998;157:894-8.

38. Crimi E, Spanevello A, Neri M, Ind PW, Rossi GA, Brusasco V. Dissociation between airway inflammation and airway hyperresponsiveness in allergic asthma. Am J Respir Crit Care Med. 1998; $157: 4-9$

39. Birrell MA, Battram CH, Woodman P, McCluskie K, Belvisi MG. Dissociation by steroids of eosinophilic inflammation from airway hyperresponsiveness in murine airways. Respir Res. 2003;4:3 [http:// www.respiratory-research/content/4/1/3]. 